\title{
A warming Southern Ocean may compromise Antarctic blue whale foetus growth
}

\author{
Carl SMITH',2
}

\begin{abstract}
${ }^{1}$ Department of Ecology \& Vertebrate Zoology, University of Łódź, Łódź, Poland; e-mail: carl.smith@biol.uni.lodz.pl
${ }^{2}$ Institute of Vertebrate Biology, Czech Academy of Sciences, Brno, Czech Republic
\end{abstract}

Received 16 October 2020; Accepted 11 March 2021; Published online 2 April 2021

\begin{abstract}
After declining in abundance due to commercial whaling during the $20^{\text {th }}$ century, populations of the Antarctic blue whale (Balaenoptera musculus intermedia) have failed to recover to pre-exploitation levels. Using historical whaling data from 1926-1954, in combination with temperature data for the Southern Ocean, a gamma GLM with temporal dependency was fitted to 20,144 records of B. m. intermedia foetus size using Bayesian inference. There was a negative relationship between antecedent winter sea surface temperature (SST) in the Southern Ocean on foetus size. This relationship is proposed as being mediated by a positive effect of the extent of winter sea ice on Antarctic krill (Euphasia superba) abundance on which B. m. intermedia feed. There was also a positive density-dependent effect of a "krill surplus" at low B. m. intermedia population sizes. However, the positive effect of a "krill surplus" at low B. m. intermedia population size on foetus growth was reversed at elevated winter SST due to a proposed negative impact on E. superba recruitment. Projected increases in temperature in the Southern Ocean are predicted to compromise the growth rates of B. m. intermedia foetuses, with implications for the capacity of the subspecies to recover from overexploitation.
\end{abstract}

Key words: Antarctica, cetacean, density dependence, IWC, population dynamics, recovery

\section{Introduction}

The large-scale harvest of baleen whales (Balaenopteridae) in the Southern Ocean, which began at the start of the $20^{\text {th }}$ century, saw rapid declines in the abundance of blue (Balaenoptera musculus), humpback (Megaptera novaeangliae), fin (Balaenoptera physalus) and sei (Balaenoptera borealis) whales (Baker \& Clapham 2004). After several decades of protection, populations of these whales have shown varying degrees of recovery (Best 1993, Clapham et al. 1999, Branch et al. 2004). Megaptera novaeangliae have shown strong recovery, $B$. physalus populations have broadly shown increases in numbers, while the status of
B. borealis populations is poorly known (Thomas et al. 2016). Balaenoptera musculus populations show wide variation in status and recovery; some populations have disappeared entirely or remain at extremely low levels (Thomas et al. 2016), while at least one population from the eastern North Pacific appears to have recovered to pre-exploitation levels (Monnahan et al. 2015). The Antarctic blue whale (Balaenoptera musculus intermedia) is classified as Critically Endangered (Reilly et al. 2008). Prior to the onset of commercial whaling the abundance of $B$. m. intermedia was estimated at approximately 239,000 individuals. Abundance declined to as few as 370 individuals, despite a moratorium on the hunting of this species in 1965 (Branch et al. 2004). 
The most recent conservative population estimate for this subspecies was 2,280 individuals, barely $1 \%$ of pre-exploitation levels (Branch 2007).

The underlying reasons for the slow recovery of $B$. $m$. intermedia have not been identified but may, in part, arise from illegal hunting by the Soviet Union into the 1970s, as well as from on-going mortalities associated with boat strikes and entanglement in fishing gear (Yablokov 1994, Clapham et al. 1999). An additional explanation for their slow recovery could relate to a decline in food availability, particularly of Antarctic krill (Euphasia superba) on which B. m. intermedia feed almost exclusively (Bannister 2008). In the southern hemisphere, $B$. $m$. intermedia migrate to Antarctic waters to feed during the austral summer, before migrating back to lower latitudes for the remainder of the year, where feeding is typically more limited, though there are departures from this general pattern (Hucke-Gaete et al. 2018). The period spent feeding is critical (Mackintosh 1965, Hucke-Gaete et al. 2018), particularly as females arrive in the Southern Ocean pregnant, with foetal growth contingent on the accumulation of energy reserves by the mother on the feeding grounds (Christiansen et al. 2014).

Euphasia superba are an important species in the Southern Ocean (Fraser \& Hofmann 2003), feeding on blooms of phytoplankton at the edge of the Antarctic sea ice with their abundance closely linked to the extent of ice (Brierley et al. 2002, Braithwaite et al. 2015). Declines in the extent and duration of Antarctic winter sea ice since the 1970s have resulted in a decline in the abundance of E. superba (Atkinson et al. 2004, Nicol 2006), with potential consequences for the predators that rely on them, including baleen whales (Alonzo \& Mangel 2001, Reid \& Croxall 2001, Ainley et al. 2006, 2007). Braithwaite et al. (2015) linked the extent of sea ice with the quantity of oil extracted from the carcasses of humpback whales caught during commercial whaling between 1947-1963. They showed that the extent of winter sea ice correlated positively with oil yields, suggesting that $M$. novaeangliae body condition was directly linked to E. superba abundance, mediated by the extent of sea ice.

Balaenopterid whales display the highest foetal growth rates of all mammals (Frazer \& Huggett 1973), demanding substantial allocation of maternal somatic resources for embryonic and foetal growth (Lockyer 1986). Rapid foetal growth in marine mammals permits the production of large neonates with high survival rates (Boltnev et al. 1998, McMahon et al. 2003), and in the case of balaenopterid whales is synchronised with their annual feeding migration from low to high latitudes (Chivers 2008). Energy supplied to the developing foetus comes from reserves accumulated during the intense feeding phase of their annual migratory cycle. If female condition is compromised, the outcome is a decline in fertility (Williams et al. 2013) and reduced investment in embryonic and foetal growth (Christiansen et al. 2014), with potential negative consequences for calf survival (Lockyer 2007).

Declines in balaenopterid population size due to whaling can release resources (a "krill surplus") to survivors and thereby facilitate recovery through density-dependent effects (Laws 1977, Fraser et al. 1992, Best 1993, Ainley et al. 2007). Density-dependent population growth has been demonstrated in B. physalus (Williams et al. 2013). However, while there is some evidence for the modest recovery of B. m. intermedia (Branch 2008), the continued low abundance of this species means that it remains critically endangered.

Here I indirectly test whether foetal growth of $B$. $m$. intermedia is determined by the availability of E. superba by examining the effect of temperature on B. m. intermedia foetal body size. A prediction is that a reduction in the extent of sea ice in response to elevated temperatures in the Southern Ocean will suppress E. superba productivity thereby compromising B. m. intermedia foetus development with negative consequences for their subsequent post-natal survival to maturity. An additional prediction is that a decline in the abundance of $B . m$. intermedia will result in a "krill surplus", detectable as increased foetus growth rate. A further prediction is that these processes are linked, with temperatures in the Southern Ocean interacting with the effect of adult $B$. m. intermedia abundance. Thus, a combination of low winter temperatures combined with low B. m. intermedia abundance are predicted to enhance foetal growth rates while the converse, elevated winter temperatures and high adult abundances, would tend to supress foetal growth as a consequence of reduced krill availability. I test these scenarios using historical whaling records and temperature data to model $B$. $m$. intermedia foetus size in response to sea surface temperature (SST) and B. m. intermedia abundance. I also conduct an independent test of this idea 
by correlating commercial whale oil production from the Southern Ocean with winter SST, with the prediction that at higher temperatures $E$. superba productivity, and consequently feeding conditions for baleen whales, would be reduced with a subsequent decline in the average yield of oil extracted from whale carcasses.

\section{Material and Methods}

Data

Blue whale data came from International Whaling Statistics (IWS) database (www.iwc.int) and included measurements of pregnant female body length and foetus length, whether the foetus was single or a twin, along with the date of capture (www.iwc.int). The complete dataset comprised 20,144 complete records spanning 30 years from 1925-1954 with data grouped by Antarctic whaling season, spanning the austral summer (OctoberMarch). Data for the whaling seasons 1940-1946 were missing due to limited hunting during WWII and its immediate aftermath. Oil yields from commercial whaling also came from IWS records and comprised average production of oil for whales landed at South Georgia. These data represent oil yields for all baleen whale species and were taken as an indication of the body condition of whales in the Southern Ocean in a given season. SST anomaly data for the Southern Ocean came from the HadISST1 data set, which comprises a globally complete SST dataset from 1871 onwards at a spatial resolution of $1^{\circ}$ latitude by $1^{\circ}$ longitude, compiled by the UK Met Office Hadley Centre (www.metoffice.gov.uk/hadobs/hadisst) (details in Rayner et al. 2003). A nominal day of conception for $B$. $m$. intermedia of $1^{\text {st }}$ August was used to estimate the day of gestation on which a pregnant female was killed and its foetus collected. This date was based on an analysis by Roston et al. (2013), which used previous published studies combined with IWS data and assuming a gestation period of 350 days. While the evidence indicates this date represents a peak in conception frequency, there is a potentially wide temporal window in the timing of conception in this species. While time-series data for E. superba abundance in the Southern Ocean are available (Atkinson et al. 2017), and could potentially be used to link food abundance with foetus size, for the period of this study these data are incomplete.

Density-dependent effects on foetus size were modelled using the total cumulative catch of $B$. $m$. intermedia in the whaling season preceding the one in which a foetus was collected. Balaenoptera musculus intermedia catch data came from Branch (2008) and included a correction for Soviet misreporting of catches. Catch data, rather than estimated population size, was used as an inverse index of abundance since catch data were relatively reliably recorded, while estimates of population size necessarily include a margin of error (Christensen 2006).

\section{Data analysis}

Beforeapplyingstatisticalmodels, adataexploration was undertaken following the protocol described in Smith et al. (2020). The data were examined for outliers in the response and explanatory variables, homogeneity of the response variable and the nature of relationships between the response and explanatory variables. Collinearity between explanatory variables was examined using co-plots and by estimating variance inflation (VIF). Model covariates were not collinear and VIF of covariates in the model were all $<2$. Model assumptions were verified by plotting model residuals against fitted values, each covariate in the model and covariates not included in the model. Model residuals were additionally assessed for evidence of non-linearity (Smith et al. 2020). Twin foetuses, of which there were 312 in the complete dataset, were consistently smaller that singletons and were dropped from the analysis. If twin foetuses were retained in the model the qualitative outcomes were identical.

Data were modelled using $\mathrm{R}$ (version 4.0.2; $\mathrm{R}$ Development Core Team 2020) with models fitted in a Bayesian framework using Integrated Nested Laplace Approximation (R-INLA; Rue et al. 2017). The advantage of using Bayesian inference was that it provides probability distributions for model parameters of interest, so that probability statements about the magnitude of model parameters can be made with confidence. This approach avoids reliance on hypothesis testing and $P$-values, which are increasingly recognised as unreliable statistical tools (Burnham \& Anderson 2014, Nuzzo 2014, Wasserstein \& Lazar 2016). Foetus size was modelled with a gamma GLM formulated as:

$$
\begin{aligned}
& \text { Foetus }_{i t} \sim \text { Gamma }\left(\mu_{i t^{\prime}} \phi\right) \\
& E\left(\text { Foetus }_{i t}\right)=\mu_{i t} \text { and var }\left(\text { Foetus }_{i t}\right)=\frac{\mu^{2}}{\phi} \\
& \log \left(\mu_{i t}\right)=\text { Intercept }^{2} f(\text { Day })+\text { Female }_{i t}+\text { Catch }_{i t} \times S S T_{i t}
\end{aligned}
$$



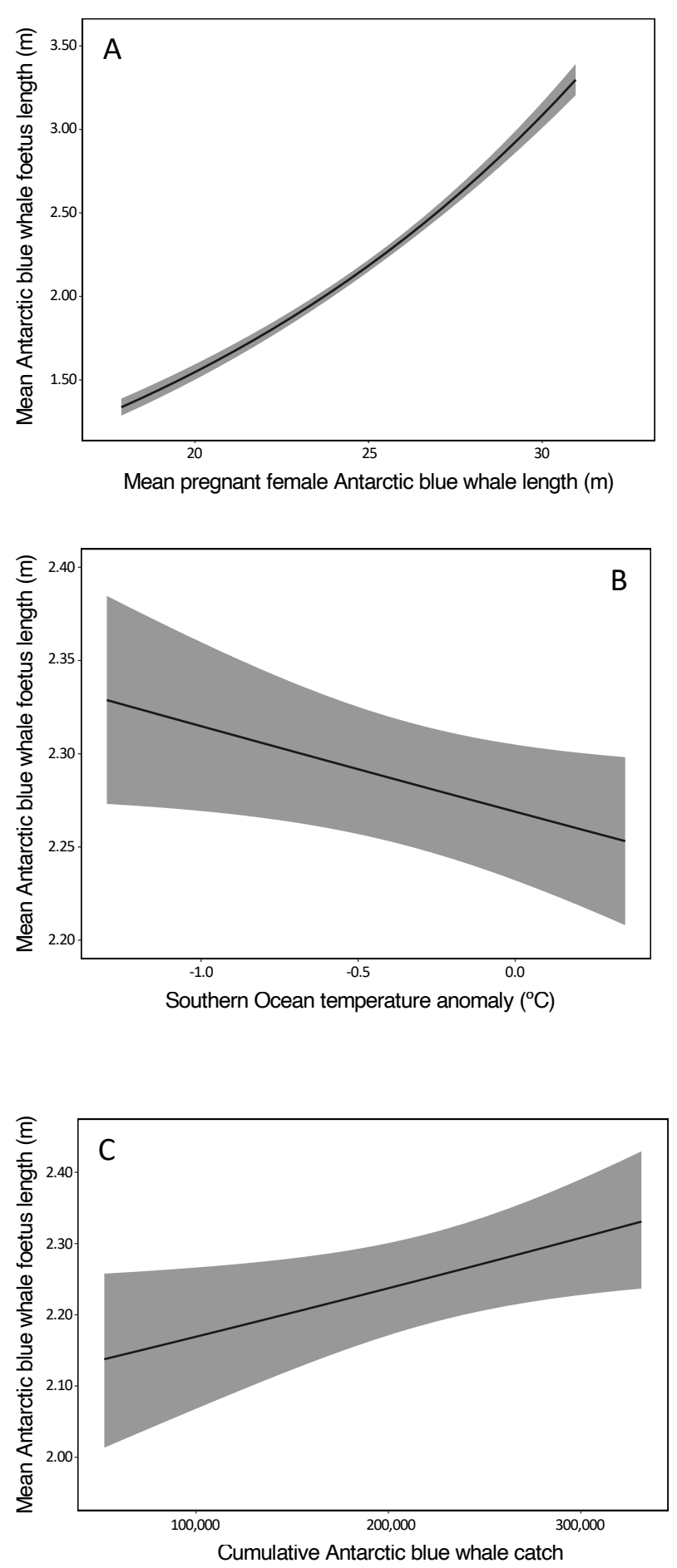

Fig. 1. Mean (solid line) fitted Antarctic blue whale (Balaenoptera musculus intermedia) foetus length $(\mathrm{m})$, with $95 \%$ credible intervals (shaded area), as a function of: A) Pregnant female Antarctic blue whale body length (m); B) Antecedent winter sea surface temperature (SST) anomaly in the Southern Ocean $\left({ }^{\circ} \mathrm{C}\right)$; C) Cumulative B. m. intermedia catch.

Where Foetus ${ }_{i t}$ is the mean size of dissected foetus $i$ on day of gestation $t$. The parameter $\phi$ is a dispersion parameter (Zuur et al. 2017). Day of gestation (Day) is included as a seasonal component modelled as a random walk trend (rw1). The model contained linear effects for pregnant female length
(Female), cumulative B. m. intermedia catch in the whaling season preceding the one in which the foetus was collected (Catch), and mean SST of the Southern Ocean for the preceding austral winter (April-September) (SST). Non-informative priors were put on residual variance $(d)$ and the posterior marginal of the precision $(t)$, with Jeffreys prior $\left(a_{1}\right.$ $\left.=b_{1}=0\right)$ on $d$ and a Gelman (2006) recommended prior $\left(a_{2}=-0.5, b_{2}=0\right)$ on $t$. Priors on betas were: intercept 0, 0; Female 0, 0.001; Catch 0, 0.001; SST 0, 0.001; Catch:SST 0, 0.001. A random term for whaling season was not included in the model. The same whales were not captured in different whaling seasons, and variance in foetus size among seasons is instead modelled as a response to SST and cumulative B. m. intermedia catch.

Because the window of conceptions for B. $m$. intermedia is potentially wide (Roston et al. 2013), any consistent environmental effects on the time of conception could undermine conclusions relating to effects of environmental temperature and foetus size. To accommodate this possibility, a model was also fitted to the difference between observed foetus size and fitted estimates of foetus size as a function of mean SST for the preceding austral winter using a Gaussian GLM, with the prediction that any relationship between foetus size and SST (either positive or negative) would indicate an association between conception date and antecedent winter SST. Whale oil production was modelled as a Gaussian GLM, fitted as:

$\mathrm{Oil}_{i} \sim N\left(\mu_{i^{\prime}} \sigma^{2}\right)$

$E\left(\mathrm{Oil}_{i}\right)=\mu_{i}$ and $\operatorname{var}\left(\mathrm{Oil}_{i}\right)=\sigma^{2}$

$\mu_{i}=$ Intercept + Catch $_{i}+S S T_{i}$

Where $\mathrm{Oil}_{i}$ was the average production (tonnes) of whale oil for whaling season $i$.

\section{Results}

There was a statistically important negative interaction between cumulative B. $m$. intermedia catch and SST anomaly on B. m. intermedia foetus size (Table 1). Female B. m. intermedia body size was positively associated with foetus size, after controlling for variance in day of gestation, SST anomaly and B. m. intermedia catch (Table 1, Fig. 1A). Foetus size was negatively associated with SST anomaly (Fig. 1B), but positively with cumulative B. m. intermedia catch in the whaling season preceding the one in which the foetus was collected (Fig. 1C). The negative interaction 

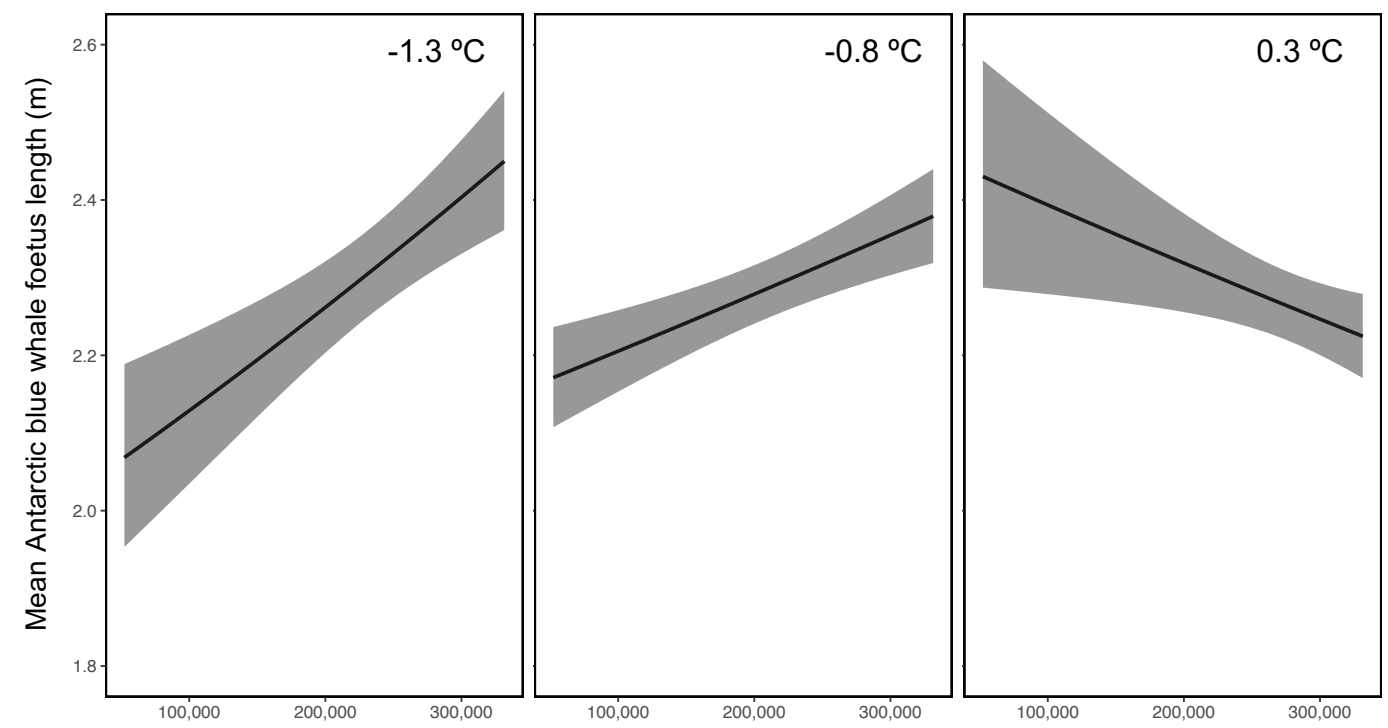

Cumulative Antarctic blue whale catch

Fig. 2. Mean (solid line) fitted Antarctic blue whale (Balaenoptera musculus intermedia) foetus length (m), with $95 \%$ credible intervals (shaded area), as a function of cumulative B. m. intermedia catch, at three antecedent winter sea surface temperature (SST) anomalies $\left(-1.3,-0.8,0.3^{\circ} \mathrm{C}\right)$.

Table 1. Posterior mean estimates of Balaenoptera musculus intermedia foetus size modelled using a random walk gamma GLM fitted using INLA. Crl is the $95 \%$ Bayesian credible interval. Credible intervals that do not encompass zero in bold to indicate statistical importance. Female size is the length of pregnant female B. $m$. intermedia from which foetuses were taken. SST is the mean sea surface temperature anomaly of the Southern Ocean for the preceding austral winter (April-September). Catch is the cumulative catch of B. $m$. intermedia in the preceding whaling season.

\begin{tabular}{lccc}
\hline Model parameter & Posterior mean & Lower CrI & Upper CrI \\
\hline Intercept & $\mathbf{0 . 8 3 1}$ & $\mathbf{0 . 8 1 5}$ & $\mathbf{0 . 8 4 8}$ \\
Female size & $\mathbf{0 . 0 9 0}$ & $\mathbf{0 . 0 8 5}$ & $\mathbf{0 . 0 9 6}$ \\
Catch & -0.006 & -0.017 & 0.004 \\
SST & -0.003 & -0.025 & 0.018 \\
Catch $\times$ SST & $-\mathbf{0 . 0 3 3}$ & $-\mathbf{0 . 0 5 2}$ & $\mathbf{- 0 . 0 1 4}$ \\
\hline
\end{tabular}

Table 2. Posterior mean estimates of the difference between observed foetus size and model estimates of foetus size as a function of antecedent winter sea surface temperature (SST) anomaly in the Southern Ocean modelled using a Gaussian GLM fitted using INLA. CrI is the $95 \%$ Bayesian credible interval. If credible intervals do not encompass zero it indicates statistical importance.

\begin{tabular}{lccc}
\hline Model parameter & Posterior mean & Lower CrI & Upper CrI \\
\hline Intercept & 0.002 & -0.020 & 0.024 \\
SST & 0.006 & -0.037 & 0.049 \\
\hline
\end{tabular}

Table 3. Posterior mean estimates of average yield of whale oil modelled as a Gaussian GLM fitted using INLA. Crl is the $95 \%$ Bayesian credible interval. Credible intervals that do not encompass zero in bold to indicate statistical importance. SST is the mean sea surface temperature anomaly of the Southern Ocean for the preceding austral winter (April-September). Catch is the cumulative catch of Balaenoptera musculus intermedia in the preceding whaling season.

\begin{tabular}{lccc}
\hline Model parameter & Posterior mean & Lower CrI & Upper CrI \\
\hline Intercept & $-\mathbf{0 . 0 4 4}$ & $-\mathbf{0 . 0 5 7}$ & $-\mathbf{0 . 0 3 1}$ \\
Catch & 0.844 & 0.835 & $\mathbf{0 . 8 5 3}$ \\
SST & $-\mathbf{0 . 1 1 2}$ & $-\mathbf{0 . 1 3 9}$ & $-\mathbf{0 . 0 8 5}$ \\
\hline
\end{tabular}




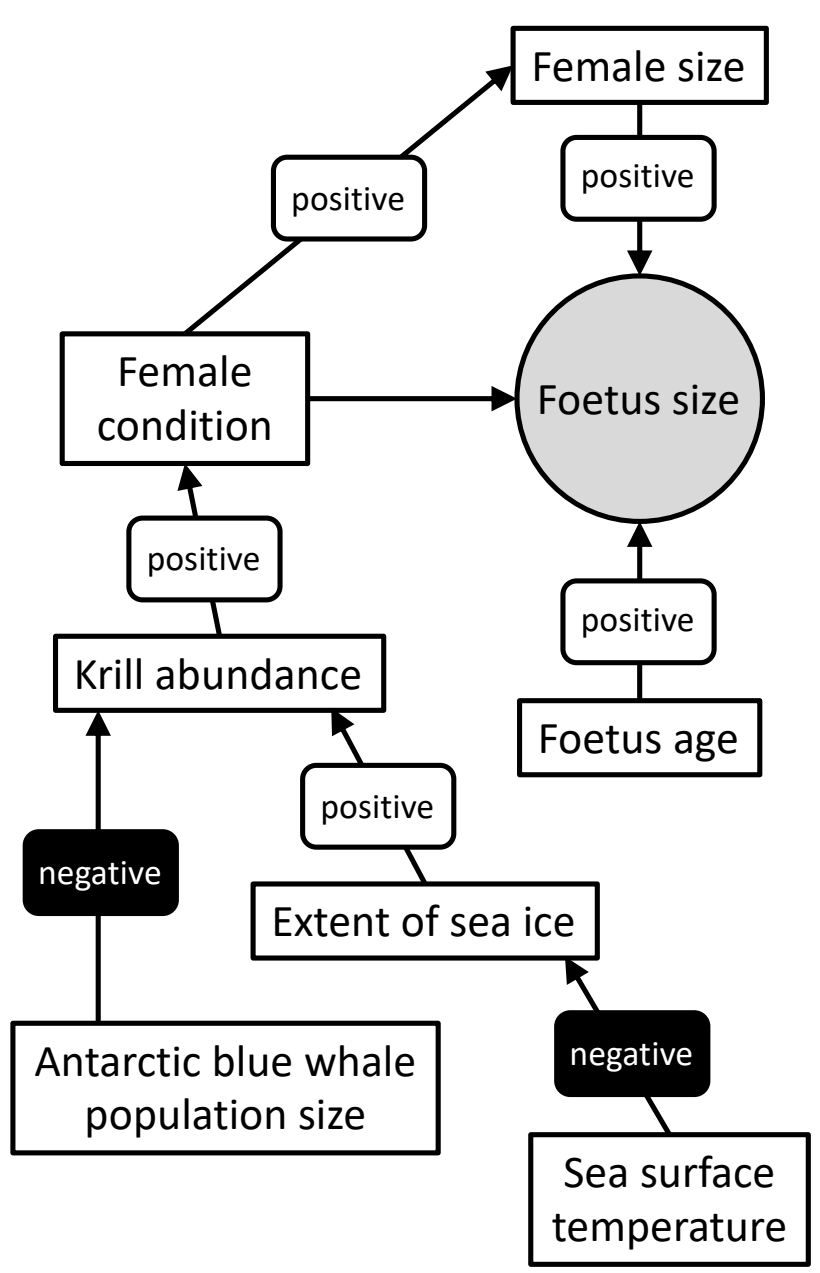

Fig. 3. Conceptual model for Antarctic blue whale (Balaenoptera musculus intermedia) foetus size. Foetus age, female body size and condition, and krill abundance are positively associated with foetus size. Extent of Antarctic sea ice is positively associated with krill abundance, while the size of the Antarctic blue whale population is negatively associated with krill abundance. Sea surface temperature is negatively associated with the extent of sea ice.

between $B$. m. intermedia catch and SST anomaly on $B . m$. intermedia foetus size showed that the positive effect of reduced blue whale density was reversed at high SST (Fig. 2). The smoother for day of gestation showed a strong positive temporal trend (Fig. S1). A partial autocorrelation function plot confirmed that autocorrelation was effectively explained by the lag-1 (rw1) autocorrelation (Fig. S2). Estimates of $\sigma_{\varepsilon}$ and $\sigma_{v}$ were 0.412 and 0.0266 respectively (Fig. S3).

Model estimates of foetus size over time showed a comparable trend to observed data (Fig. S4). Similarly, there was no association between observed foetus size and fitted estimates of foetus size as a function of mean SST (Fig. S5) indicating that, while there was substantial variability around the nominal day of conception of $1^{\text {st }}$ August, there was no association between conception date and SST (Table 2). The body size of pregnant B. $m$. intermedia over the period for which data are presented showed no trend, either upward or downward (Fig. S6).

Average oil yield for a given whaling season was positively associated with cumulative $B . m$. intermedia catch (Table 3), with average whale oil yields higher when $B$. m. intermedia abundance was lowest. In contrast, oil yields were negatively correlated with winter SST anomaly (Table 3), with higher average oil yields in whaling seasons preceded by colder winters (Fig. S7).

\section{Discussion}

A statistically important negative interaction between SST anomaly in the Southern Ocean and abundance of adult B. m. intermedia on foetus growth was detected (Fig. 2, Table 1). Elevated winter temperatures in the Southern Ocean are associated with weak E. superba recruitment through limitation of the extent and duration of winter sea ice (Brierley et al. 2002, Atkinson et al. 2004, Braithwaite et al. 2015). A low abundance of E. superba, the main component of the diet of B. $\mathrm{m}$. intermedia (Bannister 2008), is predicted to have a negative effect on foetus growth. At the same time, the cumulative catch of $B$. m. intermedia through whaling was predicted to have a positive effect on foetus growth, through the greater abundance of $E$. superba as the population declined under hunting pressure (Laws 1977, Fraser et al. 1992; Fig. 1C). The interaction between SST and B. m. intermedia catch on foetus size demonstrates that a positive effect of reduced blue whale density can be reversed at high SST (Fig. 2). An implication of this result is that while low Antarctic blue whale population size is predicted to result in increased foetal sizeat-age through positive density dependence, increased temperatures in the Southern Ocean may offset any positive effects of reduced adult density through reduced recruitment of E. superba (Fig. 3).

The fitness consequences of reduced foetus size in B. m. intermedia are not known, but compromised feeding by pregnant females is associated with reproductive failure in other marine vertebrates. In Adélie penguins (Pygoscelis adeliae), foraging and breeding performance is closely linked to $E$. superba abundance and extent of sea ice (Fraser \& Hofmann 2003). Similarly, Brierley et al. (1997) showed a direct link between fluctuation 
in E. superba abundance and the reproductive performance of gentoo (Pygoscelis papua) and macaroni penguins (Eudyptes chrysolophus). In marine mammals, pregnant females in poor condition limit investment in foetus growth. In the minke whale (Balaneoptera acutorostrata) investment in foetal growth by females is in direct proportion to body condition, which is a function of feeding success by pregnant females (Christiansen et al. 2014). Near-term foetal body weight was reported to be lower in years with diminished female body condition and feeding conditions in Icelandic populations of B. physalus (Lockyer 1990, 2007). Feeding conditions were also shown to be related to blubber thickness and pregnancy rates in $B$. physalus (Lockyer 1986, Williams et al. 2013). In southern right whales (Eubalena australis), calf abundance between 1997-2013 off the coast of southern Brazil correlated positively with E. superba abundance in the waters around South Georgia nine months earlier (Seyboth et al. 2016). Calving success of the same population between 1971-2000 was further shown to be negatively correlated with SST at South Georgia the previous year (Leaper et al. 2006), demonstrating a link between SST, E. superba abundance and reproductive success. The impacts of nutritional stress on the development and early survival of offspring of pregnant females are well described in a range of taxa (Lindström 1999), including marine mammals in which poorly provisioned foetuses experience slow growth and, following parturition, suffer reduced survival rates through an elevated risk of starvation, greater susceptibility to predation and reduced buoyancy (Boltnev et al. 1998, McMahon et al. 2000, 2003, Reeves et al. 2001, Lockyer 2007).

The data presented here span 30 years, from 19251954. In the interval following this period, the extent of Antarctic sea ice and duration of the sea-ice season have declined sharply, in association with elevated SST in the Southern Ocean (de la Mare 1997, Jacobs \& Cosimo 1997, Smith \& Stammerjohn 2001), with well-characterised negative effects on E. superba abundance (Brierley et al. 2002, Atkinson et al. 2004). The impact of these trends on the fitness of $B . m$. intermedia, have hitherto not been demonstrated, though several authors have considered the likely knock-on effects of declining E. superba stocks on baleen whale populations (Brierley et al. 1997, 2002, Braithwaite et al. 2015). The implications of the present analysis are that the fitness of B. m. intermedia will be compromised by reduced E. superba stocks through a negative effect on foetal growth, undermining any positive density-dependent effects through a "krill surplus" at low B. $m$. intermedia abundance. This finding offers a potential explanation for the failure of B. $m$. intermedia to show recovery to anything approaching pre-exploitation levels, with reduced food availability in Antarctic waters predicted to result in under-sized calves with low predicted survival rates. With the prospect of a $95 \%$ decline in E. superba stocks in regions of the Southern Ocean over the coming century in response to an increase of $1-2{ }^{\circ} \mathrm{C}$ in SST (Murphy et al. 2007), strong recovery of $B$. m. intermedia populations, in consequence, appears uncertain.

Because foetuses were not aged, the results presented here could be explained through environmental effects on the time of conception in B. m. intermedia, rather than effects on foetal growth rates. Thus, if conception dates were later in years with high SST in the Southern Ocean the same effect would be observed, with smaller foetuses, on average, on a given day of the year, but unrelated to the nutritional state of the female. Model estimates of foetus size-at-age closely matched observed data, though with lower variance since fitted foetus sizes are free from variation related to the dispersion of the observations (Fig. S4). Some of this difference in variance could be attributed to inaccuracies in the measurement and recording of foetal lengths and with variation in pregnant female condition and foetal growth rates (Frazer \& Huggett 1973). However, an additional explanation for this disparity in predicted and observed size-at-age could be a wider window in which conceptions occurred than assumed. Despite this disparity, there was no evidence for a directional effect of time of conception as a function of environmental conditions in the data (Fig. S5), indicating that model predictions did not differ systematically from observed as a function of temperature. There is also no obvious mechanism by which conception dates might be influenced by SST in the Southern Ocean, since breeding in B. $m$. intermedia takes place at low latitudes during the preceding winter (Roston et al. 2013), though it may influence ovulation. In addition, the data showed clear evidence of density dependence in foetus growth, with a positive relationship between foetus size and cumulative B. m. intermedia catch (Fig. 1C), which indicates foetal sensitivity to female feeding conditions as predicted. Further, the commercial oil yield from baleen whales caught in the Antarctic over the study period was 
independently predicted both by SST anomaly and B. m. intermedia catch (Table 3, Fig. S7). If oil yield is taken as an indication of the condition of baleen whales in the Southern Ocean in a given year (Braithwaite et al. 2015), this relationship provides circumstantial evidence that winter SST anomaly is a driver of balaenopterid feeding conditions, with direct implications for foetal development rates (Roston et al. 2013).

Another potential caveat to this study stems from a temporal shift in whalers taking B. m. intermedia to the capture of the smaller pygmy blue whale (B. m. brevicauda). However, this switch came in the early 1960s, approximately a decade after the period for which data are presented here (Branch et al. 2004, Branch 2007). It is notable that pregnant female body size showed no trend, either upward or downward, over the period for which data are presented (Fig. S6), suggesting that pregnant B. m. brevicauda did not make a significant contribution to the catch, if at all. Similarly, while the impact of commercial fisheries for finfish and E. superba on the trophic structure of the Southern Ocean have been substantial (Hill et al. 2006), the onset of commercial fishing in the Southern Ocean came over a decade after the end of the period for which data are presented (Kock 1994).
In conclusion, the analysis presented here provides circumstantial evidence for a negative relationship between $B$. m. intermedia foetus size and antecedent winter SST in the Southern Ocean. The influence of winter temperature on foetus size is most likely mediated by the positive effect of the extent and duration of winter sea ice on E. superba abundance. The effect of winter temperature was shown to interact with B. m. intermedia abundance, with a positive density-dependent effect of a "krill surplus" at low whale population sizes lost at elevated winter SST. The effect of predicted SST rises of $1-2{ }^{\circ} \mathrm{C}$ in the Southern Ocean (Murphy et al. 2007) are anticipated to compromise the growth of B. m. intermedia foetuses, with implications for the capacity of the sub-species to recover from overexploitation.

\section{Acknowledgements}

Iamgrateful to Trevor Branch, Andy Brierley and Rowena Spence for comments, and to John Smith for meticulous data compilation. Research ideas were formulated while supported by the POLONEZ Fellowship of National Science Centre, Poland (2015/19/P/NZ8/03582), which received funding from the European Union's Horizon 2020 research and innovation program under the Marie Skłodowska-Curie grant agreement No. 665778. 


\section{Literature}

Ainley D., Ballard G., Ackley S. et al. 2007: Paradigm lost, or is top-down forcing no longer significant in the Antarctic marine ecosystem? Antarct. Sci. 19: 283-290.

Ainley D., Toniolo V., Ballard G. et al. 2006: Managing ecosystem uncertainty: critical habitat and dietary overlap of top-predators in the Ross Sea. CCAMLR document WGEEM-06/29, Hobart, Tasmania, Australia.

Alonzo S.H. \& Mangel M. 2001: Survival strategies and growth of krill: avoiding predators in space and time. Mar. Ecol. Prog. Ser. 209: 203217.

Atkinson A., Hill S.L., Pakhomov E. et al. 2017: KRILLBASE: a circumpolar database of Antarctic krill and salp numerical densities, 1926-2016. Earth Syst. Sci. Data 9: 193-2107.

Atkinson A., Siegel V., Pakhomov E. \& Rothery P. 2004: Long-term decline in krill stock and increase in salps within the Southern Ocean. Nature 432: 100-103.

Baker C.S. \& Clapham P.J. 2004: Modelling the past and future of whales and whaling. Trends Ecol. Evol. 19: 365-371.

Bannister J.L. 2008: Baleen whales (mysticetes). In: Perrin W.F., Würsig B. \& Thewissen J.G.M. (eds.), Encyclopedia of marine mammals, $2^{\text {nd }}$ ed. Academic Press, New York: 80-89.

Best P.B. 1993: Increase rates in severely depleted stocks of baleen whales. ICES J. Mar. Sci. 50: 169-186.

Boltnev A.I., York A.E. \& Antonelis G.A. 1998: Northern fur seal young: interrelationships among birth size, growth, and survival. Can. J. Zool. 76: 843-854.

Braithwaite J.E., Meeuwig J.J., Letessier T.B. et al. 2015: From sea ice to blubber: linking whale condition to krill abundance using historical whaling records. Polar Biol. 38: 1195-1202.

Branch T.A. 2007: Abundance of Antarctic blue whales south of $60{ }^{\circ} \mathrm{S}$ from three complete circumpolar sets of surveys. J. Cetacean Res. Manag. 9: 87-96.

Branch T.A. 2008: Biological parameters for pygmy blue whales. International Whaling Commission Document SC/60/SH6: 13.

Branch T.A., Matsuoka K. \& Miyashita T. 2004: Evidence for increases in Antarctic blue whales based on Bayesian modelling. Mar. Mamm. Sci. 20: 726-754.

Brierley A.S., Fernandes P.G., Brandon M.A. et al. 2002: Antarctic krill under sea ice: elevated abundance in a narrow band just south of ice edge. Science 295: 1890-1892.

Brierley A.S., Watkins J.L. \& Murray A.W. 1997: Interannual variability in krill abundance at South Georgia. Mar. Ecol. Prog. Ser. 150: 87-98.

Burnham K.P. \& Anderson D.R. 2014: P values are only an index to evidence: $20^{\text {th }}$ - vs. $21^{\text {st }}$-century statistical science. Ecology 95: 627-630.

Chivers S.J. 2008: Cetacean life history. In: Perrin W.F., Würsig B. \& Thewissen J.G.M. (eds.), Encyclopedia of marine mammals, $2^{\text {nd }}$ ed. Academic Press, New York: 215-220.

Christensen L.B. 2006: Marine mammal populations: reconstructing historical abundances at the global scale. Fisheries Centre Research Reports 14. University of British Columbia, Vancouver.

Christiansen F., Víkingsson G.A., Rasmussen M.H. \& Lusseau D. 2014: Female body condition affects foetal growth in a capital breeding mysticete. Funct. Ecol. 28: 579-588.

Clapham P.J., Young S.B. \& Brownell R.L. 1999: Baleen whales: conservation issues and the status of the most endangered populations. Mammal Rev. 29: 37-62.

de la Mare W.K. 1997: Abrupt mid-twentiethcentury decline in Antarctic sea-ice extent from whaling records. Nature 389: 57-60.

Fraser W.R. \& Hofmann E.E. 2003: A predator's perspective on causal links between climate change, physical forcing and ecosystem response. Mar. Ecol. Prog. Ser. 265: 1-15.

Frazer J.F.D. \& Huggett A.S.G. 1973: Specific foetal growth rates of cetaceans. J. Zool. 169: 111-126.

Fraser W.R., Trivelpiece W.Z., Ainley D.G. \& Trivelpiece S.G. 1992: Increases in Antarctic penguin populations: reduced competition with whales or a loss of sea ice due to global warming? Polar Biol. 11: 525-531.

Gelman A. 2006: Prior distributions for variance parameters in hierarchical models. Bayesian Anal. 1: 515-533.

Hill S.L., Murphy E.J., Reid K. et al. 2006: Modelling Southern Ocean ecosystems: krill, the foodweb, and the impacts of harvesting. Biol. Rev. 81: 581-608.

Hucke-Gaete R., Bedriñana-Romano L., Viddi F.A. et al. 2018: From Chilean Patagonia to Galapagos, Ecuador: novel insights on blue whale migratory pathways along the Eastern South Pacific. PeerJ 6: e4695.

Jacobs S.J. \& Comiso J.C. 1997: Climate variability in the Amundsen and Bellingshausen seas. J. Clim. 10: 697-709. 
Kock K.H. 1994: Fishing and conservation in southern waters. Polar Rec. 30: 3-22.

Laws R.M. 1977: Seals and whales of the Southern Ocean. Philos. Trans. R. Soc. B 279: 81-96.

Leaper R., Cooke J., Trathan P. et al. 2006: Global climate drives southern right whale (Eubalaena australis) population dynamics. Biol. Lett. 2: 289-292.

Lindström J. 1999: Early development and fitness in birds and mammals. Trends Ecol. Evol. 14: 343-348.

Lockyer C. 1986: Body fat condition in northeast Atlantic fin whales, Balaenoptera physalus, and its relationship with reproduction and food resource. Can. J. Fish. Aquat. Sci. 43: 142-147.

Lockyer C. 1990: The importance of biological parameters in population assessments with special reference to fin whales from the NE Atlantic. North Atlantic Studies 2: 22-31.

Lockyer C. 2007: All creatures great and smaller: a study in cetacean life history energetics. $J$. Mar. Biol. Assoc. U. K. 87: 1035-1045.

Mackintosh N.A. 1965: The stocks of whales. Fishing News Ltd., London.

McMahon C.R., Burton H.R. \& Bester M.N. 2000: Weaning mass and the future survival of juvenile southern elephant seals, Mirounga leonina, at Macquarie Island. Antarct. Sci. 12: 149-153.

McMahon C.R., Burton H.R. \& Bester M.N. 2003: A demographic comparison of two southern elephant seal populations. J. Anim. Ecol. 72: 61-74.

Monnahan C.C., Branch T.A. \& Punt A.E. 2015: Do ship strikes threaten the recovery of endangered eastern North Pacific blue whales? Mar. Mamm. Sci. 31: 279-297.

Murphy E.J., Trathan P.N., Watkins J.L. et al. 2007: Climatically driven fluctuations in Southern Ocean ecosystems. Proc. R. Soc. Biol. Sci. Ser. B 274: 3057-3067.

Nicol S. 2006: Krill, currents, and sea ice: Euphausia superba and its changing environment. Bioscience 56: 111-120.

Nuzzo R. 2014: Scientific method: statistical errors. Nature 506: 150-152.

R Development Core Team 2020: R: a language and environment for statistical computing. $R$ Foundation for Statistical Computing, Vienna, Austria.

Rayner N.A., Parker D.E., Horton E.B. et al. 2003: Global analyses of sea surface temperature, sea ice, and night marine air temperature since the late nineteenth century. J. Geophys. Res. Atmos. 108: 4407.
Reeves R.R., Rolland R. \& Clapham P.J. 2001: Causes of reproductive failure in North Atlantic right whales: new avenues and research. In: Reeves R.R., Rolland R. \& Clapham P.J. (eds.), Northeast Fisheries Science Center Reference Document 01-16 - report of a workshop held 26-28 April 2000. Falmouth, Massachusetts.

Reid K. \& Croxall J.P. 2001: Environmental response of upper trophic-level predators reveals a system change in an Antarctic marine ecosystem. Proc. R. Soc. Biol. Sci. Ser. B 268: 377-384.

Reilly S.B., Bannister J.L., Best P.B. et al. 2008: Balaenoptera musculus ssp. intermedia. The IUCN Red List of Threatened Species 2008: eT41713A98837960. http://www.iucnredlist.org/

Roston R.A., Lickorish D. \& Buchholtz E.A. 2013: Anatomy and age estimation of an early blue whale (Balaenoptera musculus) foetus. Anat. Rec. 296: 709-722.

Rue H., Riebler A., Sørbye S.H. et al. 2017: Bayesian computing with INLA: a review. Annu. Rev. Stat. Appl. 4: 395-421.

Seyboth E., Groch K.R., Dalla R.L. et al. 2016: Southern right whale (Eubalaena australis) reproductive success is influenced by krill (Euphausia superba) density and climate. Sci. Rep. 6: 28205.

Smith C., Uzal A. \& Warren M. 2020: Statistics in $\mathrm{R}$ for biodiversity conservation. Amazon Publishing, Seattle.

Smith R.C. \& Stammerjohn S.E. 2001: Variations of surface air temperature and sea ice extent in the Western Antarctic Peninsula (WAP) region. Ann. Glaciol. 33: 493-500.

Thomas P.O., Reeves R.R. \& Brownell R.L. 2016: Status of the world's baleen whales. Mar. Mamm. Sci. 32: 682-734.

Wasserstein R.L. \& Lazar N.A. 2016: The ASA's statement on p-values: context, process, and purpose. Am. Stat. 70: 129-133.

Williams R., Vikingsson G.A., Gislason A. et al. 2013: Evidence for density-dependent changes in body condition and pregnancy rate of North Atlantic fin whales over four decades of varying environmental conditions. ICES J. Mar. Sci. 70: 1273-1280.

Yablokov A.V. 1994: Validity of whaling data. Nature 367: 108.

Zuur A.F., Ieno E.N. \& Saveliev A.A. 2017: Spatial, temporal and spatial-temporal ecological data analysis with R-INLA. Highland Statistics Limited, Newburgh. 


\section{Supplementary online material}

Fig. S1. Fitted (solid line) random walk (rw1) smoother with $95 \%$ credible intervals (shaded area) for a gamma GLM for Antarctic blue whale (Balaenoptera musculus intermedia) foetus size against day of gestation assuming a nominal day of conception of $1^{\text {st }}$ August.

Fig. S2. Partial autocorrelation function of model residuals. Dashed horizontal line indicates $95 \%$ confidence intervals.

Fig. S3. A) Marginal posterior distribution of $\sigma_{\varepsilon}$. B) Marginal posterior distribution of $\sigma_{v}$.

Fig. S4. Difference between fitted estimates of Antarctic blue whale (Balaenoptera musculus intermedia) foetus length $(\mathrm{m})$ and observed foetus length as a function of day of gestation modelled with a random walk (rw1) gamma GLM assuming a nominal day of conception of $1^{\text {st }}$ August. Horizontal black dashed line indicates unity.

Fig. S5. Difference between fitted estimates of Antarctic blue whale (Balaenoptera musculus intermedia) foetus length $(\mathrm{m})$ and observed foetus length as a function of average Southern Ocean temperature anomaly $\left({ }^{\circ} \mathrm{C}\right)$ during the preceding austral winter (April-September). Horizontal black dashed line indicates unity.

Fig. S6. Boxplots of pregnant female Antarctic blue whale (Balaenoptera musculus intermedia) lengths $(\mathrm{m})$ caught in the 1926-1954 whaling seasons. Horizontal red dashed line indicates mean female length. $\mathrm{N}$ is the number of females measured in each whaling season.

Fig. S7. Mean (solid line) fitted baleen whale oil yield (tonnes), with $95 \%$ credible intervals (shaded area), as a function of average Southern Ocean temperature anomaly $\left({ }^{\circ} \mathrm{C}\right)$ during the preceding austral winter (AprilSeptember). 